\title{
Common causes of blindness in Zaïre
}

\author{
L KAYEMBE
}

From the University of Kinshasa Service of Ophthalmology, Kinshasa, Zaïre

SUMmARY An analysis of 50000 patients' medical records was made to determine the commonest causes of blindness in Zaïre. It was found that the commonest causes of blindness in order of frequency were glaucoma $(31 \%)$, cataract $(18 \cdot 4 \%)$, optic atrophy $(16 \cdot 3 \%)$, onchocerciasis $(4 \cdot 9 \%)$, and corneal leucoma $(4 \cdot 9 \%)$.

The definition of legal blindness varies from one country to another. To give one example of the differences, the legally blind in the USA are those whose corrected visual acuity for distance is equal or inferior to $20 / 200(6 / 60)$ or with a visual field not greater than $20^{\circ}$ in the better eye. ${ }^{12}$ But in many European and African countries persons with legal blindness are those whose corrected visual acuity is equal or inferior to $1 / 20(3 / 60)$ or whose visual field is not greater than $10^{\circ}$ in the better eye.

Studies of the predominant causes of blindness have been performed for a number of countries with different results from one country to another and in the same country from one region to another (regions of endemic onchocerciasis or trachoma, rural or urban).

The world can be schematically divided into developed and developing countries. In the first group the main causes of blindness are ocular degenerative diseases (macular degeneration, degenerative myopia, glaucoma) and diabetic retinopathy. ${ }^{13-5}$ In the second group the predominant causes of blindness are ocular infections (onchocerciasis, trachoma, keratoconjunctivitis, and corneal ulcers), malnutrition (xerophtalmia, keratomalacia, optic neuritis), glaucoma, and cataract..$^{36-11}$

In Zaire our study of the main causes of blindness had two purposes: (1) to determine the ocular diseases which cause blindness; (2) to provide prophylactic and curative treatment of them.

\section{Materials and methods}

From 1962 to 197950000 patients have been treated at the Eye Department of University Hospital of Kinshasa. The patient's identity (age, sex, ethnic group, and profession), his visual acuity, visual field,

Correspondence to Professor L. Kayembe, Université National due Zaïre, Cliniques Universitaires, BP 123 Kinshasa XI, Zaïre. and results of biomicroscopic, tonometric, and funduscopic examination were noted. The patients with visual acuity equal or inferior to $1 / 20$ (finger counting at $2.5 \mathrm{~m}$ ) and/or a visual field of less than $10^{\circ}$ (Goldmann perimeter) are considered as legal blind.

The diagnosis was made for each eye separately, but in the case of two or more diagnoses-for example, retinal detachment and cataract-retinal detachment was noted the main cause of blindness because it is the most important affection.

We have excluded from this study cases of cataract successfully operated on (with visual acuity superior to $1 / 20$ ). We consider only cataract which cannot be treated surgically for various psychological reasons (ignorance, patient's refusal).

\section{Results}

Of 50000 patients treated, 944 or $1.9 \%$, were registered as legal blind. Male blind patients were twice as common as female. The age distribution of the legal blind is shown in Table $1.24 \%$ of blind persons less than 20 years old were in the preschool or school period. The age groups $20-44$ years old $(27.6 \%)$ and $45-64$ years $(32.9 \%)$ contained $60 \%$ of the legal blind. These persons were at an active stage of life and had various professional and family responsibilities.

The incidence of the principal causes of blindness is shown in Table 1, while the distribution of the causes by sex is shown in Table 2 . Glaucoma $(31 \%)$ was by far the commonest cause of blindness in our sample. Cataract $(18.4 \%)$ and optic atrophy of various causes came in the second and the third position respectively. Affections of the optic nerve, including glaucoma and atrophy, made 448 patients blind ( 880 eyes) or about $50 \%$. Onchocerciasis was in the fourth position, with 47 legally blind $(4.9 \%)$ or 94 eyes. This figure should be regarded as minimal. 
Table 1 Leading causes of legal blindness for age groups expressed as percentage, Zaire

\begin{tabular}{|c|c|c|c|c|c|c|}
\hline \multirow[t]{2}{*}{ Causes } & \multicolumn{6}{|c|}{ Percentage of patients by age groups } \\
\hline & $0-4$ & $5-19$ & $20-44$ & $45-64$ & $65-74$ & 75 years \\
\hline 1 Glaucoma & $2 \cdot 1$ & $1 \cdot 8$ & $7 \cdot 3$ & 14 & $4 \cdot 5$ & $1 \cdot 5$ \\
\hline 2 Cataract & $3 \cdot 0$ & $1 \cdot 6$ & $1 \cdot 9$ & $6 \cdot 8$ & $4 \cdot 6$ & 0.5 \\
\hline 3 Optic atrophy & $2 \cdot 5$ & 1.9 & $6 \cdot 5$ & $4 \cdot 4$ & 0.5 & 0.5 \\
\hline 4 Onchocerciasis & - & - & $1 \cdot 4$ & $1 \cdot 9$ & $1 \cdot 6$ & - \\
\hline 5 Corneal leucoma & 0.7 & 0.5 & $2 \cdot 8$ & 0.8 & - & - \\
\hline 6 Phthsis & $0 \cdot 5$ & $0 \cdot 5$ & $2 \cdot 4$ & $0 \cdot 8$ & 0.6 & - \\
\hline 7 Hereditary retinal dystrophies & $0 \cdot 5$ & $0 \cdot 7$ & $2 \cdot 0$ & 0.9 & 0.4 & - \\
\hline 8 Retinal detachment & - & $0 \cdot 7$ & $1 \cdot 6$ & $1 \cdot 8$ & $0 \cdot 1$ & - \\
\hline 9 Congenital anomalies & $2 \cdot 7$ & $1 \cdot 2$ & - & - & - & - \\
\hline All others & $1 \cdot 5$ & $1 \cdot 6$ & $2 \cdot 6$ & $1 \cdot 5$ & 0.4 & 0.3 \\
\hline Total & $13 \cdot 5$ & $10 \cdot 5$ & $27 \cdot 6$ & 32.9 & $12 \cdot 7$ & $2 \cdot 8$ \\
\hline
\end{tabular}

Table 2 Common causes of blindness in males and females, Zaïre

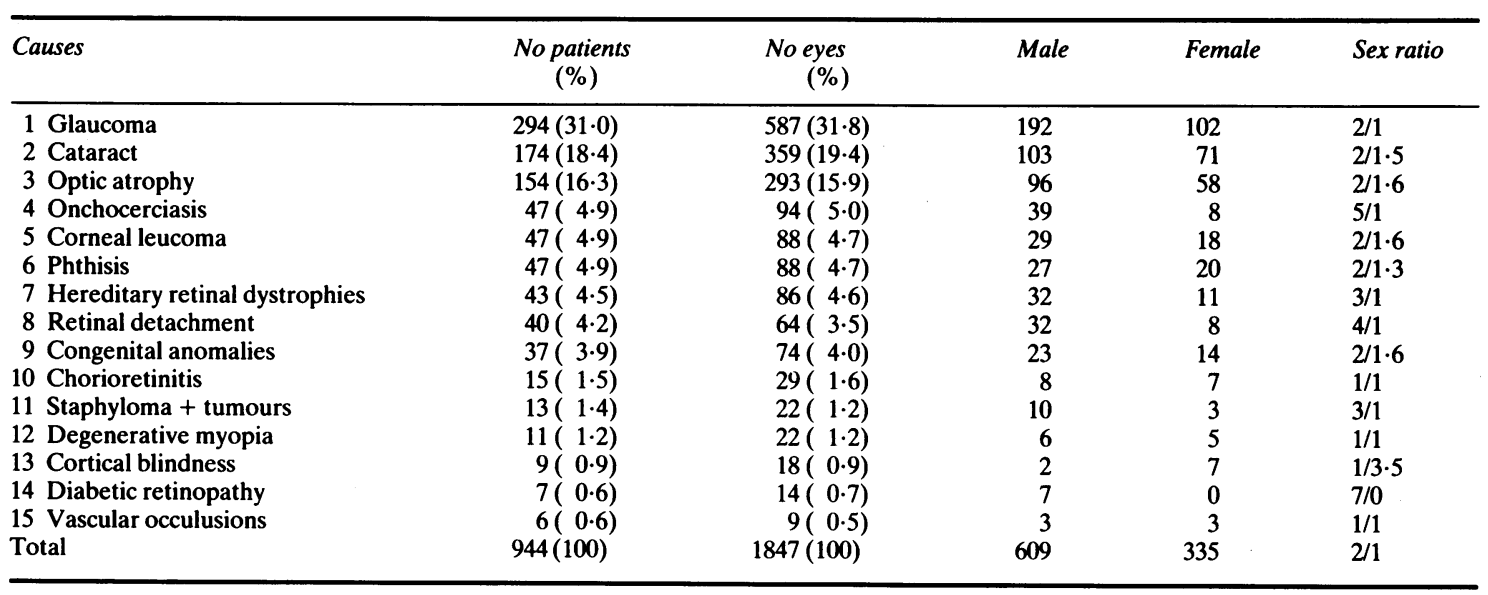

\section{Discussion}

The population of Zaire is sufficiently well represented by the patients treated at the Eye Department of the University Hospital of Kinshasa. In fact the most serious cases of blindness and visual handicap are usually referred to University Hospital for a second opinion and treatment. Nevertheless, our statistics are minimal, because some blind people cannot consult a physician either through ignorance or for financial or psychological reasons. In addition the University Hospital is situated far from some of the onchocerciasis endemic areas, such as KasaïSankuru (about $800 \mathrm{~km}$ ); this explains the moderate number of patients blind from onchocerciasis in our sample. The male-to-female ratio of 2:1 among the legal blind is to be expected because of the predominance of male persons attending at the Eye department.

The absence of a policy of registration of blind people by the National Social Security, as in other countries, makes difficult any evaluation of the incidence of blindness for the entire population of Kinshasa. ${ }^{311} 12$

In the present study the age at onset of visual defect is difficult to determine because ophthalmic examination usually takes place some time after the onset of blindness. The median time between the onset of the visual defect and diagnosis is two years. The fact that many patients are young is disturbing: $24 \%$ of them are in the age group $0-19$ years, corresponding to the preschool and school periods. The incidence of blindness increases with advancing age: respectively $52 \%$ up to 45 years and $85 \%$ up to 65 years.

\section{CAUSES}

Glaucoma, accounting for about $31 \%$, is the commonest cause of blindness in our sample. Persons with glaucoma are generally examined very late, and are difficult to treat by either the rigorous application of miotics or by surgical operation. Pilocarpine administered in high concentration $(4 \%, 6 \%)$ alone or together with timolol usually gives fairly good tonometric results. ${ }^{13}$ But pilocarpine in high concen- 
tration is rare on the market and timolol very expensive. Filtering operations for glaucoma (Elliot trepanation, trabeculectomy) can improve or stabilise the glaucoma, but in some cases no improvement is noted.

Cataract, accounting for about $18 \%$, is the second commonest cause of blindness. The contrast between our statistics and those of other studies can be explained as follows: only cataract not treatable surgically is considered here, and cataract treated with visual improvement is excluded from this study. However, the data from the present study show some points which are worthy of comment. Cataract is a specially important cause of blindness, for it affects young people, with high incidence of unilateral cataract. In India and several developing countries cataract is the principal cause of blindness. ${ }^{237811} 141516$

Optic atrophy ranks as the third cause of blindness. Different causes of it can be suggested: congenital, hereditary, toxic (from trypanosomiasis treatment with tryparsamide injections), infection (meningitis, syphilis), and after head or orbital injuries.

Onchocerciasis appeared as the fourth cause of blindness, but in some endemic areas, and villages, it becomes the commonest cause. In some villages of Kasaï such as Kasongo-Batetela, Lusambo, many persons are affected; they became blind from sclerosing keratitis, secondary glaucoma, Ridley chorioretinitis, optic atrophy, or bulbus atrophy. ${ }^{1718}$

Trachoma is a chronic keratoconjunctivitis unknown in Zaïre and is absent from our list of blinding ocular diseases. It is a more important cause of blindness in the Eastern Mediterranean, in east, the south, and south-east Asia, in Australia, and in other African countries. ${ }^{311} 16$

Xerophthalmia, in its typical form is rarely a cause of blindness in Zaïre. Keratomalacia is commonly observed in children affected by measles complicated by gastroenteritis, bronchopneumonia, malnutrition, and dehydration. It may be a herpetic infection with bacterial superinfection (pseudomonas). It is known that the prevalence of xerophthalmia is high in the rice culture regions of Asia and in other parts of Africa, America, and Asia. ${ }^{311}$
The common blinding conditions in developed countries, such as senile macular degeneration, hereditary chorioretinal dystrophies, and diabetic retinopathy are poorly represented in our statistics. $^{1241219}$

\section{References}

1 Ghafour IM, Alland D, Foulds WS. Common causes of blindness and visual handicap in the west of Scotland. $\mathrm{Br} J$ Ophthalmol 1983; 67: 209-13.

2 Roy FH. World blindness: definition, incidence and major treatable causes. Ann Ophthalmol 1974; 6: 1049-50,

3 World Health Organisation. Prévention de la cécité. Chronique OMS 1976; 30: 437-44.

4 Konstantinov N, Pencheva D. Causes of blindness among children in Bulgaria. Ophthalmologica 1977; 175: 215-21.

5 Robinson GS, Watt JA, Scott E. A study of congenital blindness in British Columbia. Epidemiological findings. Can J Ophthalmol 1969; 4: 152-62.

6 Diallo JS. Causes of blindness in Tropical Africa. Med Afr Noire 1977; 24: 563-6.

7 Massin M, Arrata M. Cécité en 1978. Concours Med Fr 1978; 100 (suppl).

8 Olurin O. Etiology of blindness of Nigerian children. Am J Ophthalmol 1970; 70: 533-40.

9 Said ME, Goldstein H, Korra A, El-Kashlan K. Prevalence and causes of blindness in a developing country. A preliminary report. Sight Sav Rev 1969; 39: 158-61.

10 Said ME, Goldstein H, Korra A, El-Kashlan K. Blindness prevalence rates in Egypt. HSMHA Rep 1972; 87: 177-84.

11 Verin PH. Les causes de cécité en Afrique. Med Afr Noire 1979; 26: 23-6.

12 Canadian National Institute of the blind. Statistical studies on the blind population of Canada registered with CNIB, 1979. Toronto: CNIB, 1981.

13 Maertens K, Kabuni M. L'effet de la pilocarpine à pourcentage élevé sur l'iris pigmenté. Bull Soc Belge Ophtalmol 1982; 201: 99-104.

14 Chartterjee A, Roy CM, Sydney T. Prevalence and aetiology of cataract in Punjab. BrJ Ophthalmol 1982; 66: 35-42.

15 Chartterjee S. Blindness in Ghana and its rehabilitation. Ghana Med J 1970; 9: 314-5.

16 Toufic $\mathrm{N}$. La cécité et ses problèmes en Afrique de l'Ouest d'expression française. Ann Oculist (Paris) 1969; 62: 724-8.

17 Maertens K. Les complications oculaires de l'onchocercose. Ann Soc Belge Med Trop 1981; 61: 199-224.

18 Maertens K. Aspects ophtalmologiques de l'onchocercose au Zaire. Ophtalmologie tropicale. Paris: Lab Merk Sharp and Dohme, 1982.

19 Abramson JM, Kark SL, Michaelson IC, Epstein LM. Prevalence and causes of blindness in Jerusalem. Isr J Med Sci 1971; 7: 268-79. 